\title{
VERSATILE ROSELLE GRAFT-COPOLYMERS : XRD STUDIES AND THEIR MECHANICAL EVALUATION AFTER USE AS REINFORCEMENT IN COMPOSITES
}

\author{
ASHISH CHAUHAN* AND BALBIR KAITH
}

\author{
Deptt. of Chemistry, Dr. B.R. Ambedkar National Institute of Technology, Jalandhar 144011 (Pb) India
}

(Received: December 29, 2011 - Accepted: May 25, 2012)

\begin{abstract}
Roselle is rich in cellulose content and exists as waste bio-mass in abundance thorough-out the world. It has low weight and high tensile strength that promotes its use as backbone for graft copolymerization. Various reaction parameters for the graft co-polymerization of effective acrylate monomer onto stem fiber were optimized and used in binary mixture with six vinyl monomers to screen the change in properties of the fiber. These graft copolymers were characterized by advanced analytical techniques and evaluated for mechanical strength after being incorporated in polymer matrix based composite as reinforcement.
\end{abstract}

\section{INTRODUCTION}

Graft copolymerization is a commendable technique for incorporating the desired properties into the raw fiber without drastically affecting its basic traits. It imparts additional features such as thermal and chemical resistance to the naturally existing back-bone for their use in various fields. Natural fibers such as ramie, flax, jute and pine needle have been widely studied by various researchers because of their relatively high strength and stiffness and for their application in industries such as automobile, packaging and construction materials that fulfill the economic and ecological requirements ${ }^{1-4}$. Cellulose, starch, chitosan, guar-gum and psylium have been modified for their use in metal ion-sorption, drug delivery and water absorption studies ${ }^{5-10}$.

Cellulosic fiber possesses both crystalline and amorphous regions. The $\mathrm{x}$-ray pattern of the crystalline polymer shows sharp peaks associated with the region of three dimensional order and the diffused features are characteristics of the molecularly disordered substances coexisting within itself. Lower crystallinity means higher amorphous content that may be more accessible to chemicals and water. Crystallinity is correlated to the strength of the fiber. On grafting crystal lattice of the polymer is disrupted but the strength of the material may add to reinforce the structure. However, if crystallinity is not affected on grafting then a continuous increase in strength can be obtained ${ }^{11-14}$

Hibiscus sabdariffa ( $H s$, Roselle) is found in abundance in nature through-out and has attained prominence as a jute substitute and attempts are being made to extend its cultivation in areas which are not favorable for jute cultivation. Good mechanical properties were found when injection-molded isotactic polypropylene/Roselle fiber composites were studied ${ }^{15-16}$, but still remain unexplored for its viability as substrate to grafting by vinyl monomers. The versatility of this chemical technique inspired the thoughts to implement it on the virgin Roselle fiber by using effective $n$-butyl acrylate as a principal monomer and its binary mixtures with acrylonitrile, 4-vinyl pyridine, methyl acrylate, acrylic acid, acrylamide and vinyl acetate to screen the change in the percentage grafting, morphology, crystallinity by FTIR, SEM and XRD studies and use the raw and the grafted fiber as reinforcement in Phenolformaldehyde polymer matrix to form fiber -reinforced- composite for its comparative mechanical accreditation. The morphological transformation after use of binary vinyl monomeric mixtures for grafting by XRD and use of Sereni graft copolymers as reinforcement in polymer matrix based composites still remains unexplored.

\section{EXPERIMENTAL}

\section{Materials}

Roselle fibers were refluxed with acetone for $72 \mathrm{~h}$. The Merck chemicals: methyl acrylate (MA), n-butyl acrylate (BA), acrylonitrile (AN), 4-vinyl pyridine (4-VP), acrylic acid (AA), acrylamide (Aam) and vinyl acetate (VA). Ceric ammonium nitrate (CAN), phenol (s. d. fine-Chem. Pvt Ltd.), formaldehyde ( $\mathrm{CDH}$, India) and concentrated nitric acid were used as received. The weighing process was carried-out on Libror AEG-220 (Shimadzu) electronic balance. FTIR spectra were recorded on a Perkin Elmer spectrophotometer and Scanning Electron Microspcopy analyses (SEM) were developed by using an Electron Microscopy Machine (LEO-435-25-20). $\mathrm{X}$-ray diffraction studies were performed on Bruker- $\mathrm{D}_{8}$ Advance. Tensile and compressive strength were studied on Universal Testing Machine (Hounsfield, H25KS).

\section{Synthesis of the graft copolymers}

Graft copolymerization of the BA monomer onto Roselle fibers was carried-out for the optimization of different reaction conditions like reaction time, reaction temperature, monomer concentration, concentration of initiator agent and $\mathrm{pH}$ in order to obtain maximum graft yield. The fiber $(0.5 \mathrm{~g})$ was activated by swelling in $100 \mathrm{~mL}$ of distilled water for $24 \mathrm{~h}$. A mixture of CAN and conc. $\mathrm{HNO}_{3}$ was added to the reaction medium under continuous stirring followed by the addition of a definite ratio of binary vinyl monomeric mixture (mentioned in Optimization of the reaction parameters) On completion of the reaction, the homo-polymers of poly (acrylates), poly (vinyl acetate), poly (acrylamide) and poly (vinyl pyridine) were removed with water, acetone, chloroform and methanol while poly (acrilonitrile) was removed with $\mathrm{N}, \mathrm{N}$ dimethylformamide. The graft copolymers were dried at $50^{\circ} \mathrm{C}$, until a constant weight was obtained ${ }^{1-3}$. Percentage of grafting was established by means of the equation 1

$$
\mathrm{Pg}=\left[\left(\mathrm{W}_{2}-\mathrm{W}_{1}\right) / \mathrm{W}_{1}\right] \times 100 \quad(\%) \quad(1)
$$

where: $\mathrm{W}_{1}$ and $\mathrm{W}_{2}$ is the weight of the original fiber and functionalized fiber, respectively.

\section{Synthesis of phenol-formaldehyde resin (PF)}

Phenol-formaldehyde resin was prepared in a resin kettle by taking specific molar ratio of phenol and formalin. Phenol and formalin were mixed with the help of mechanical stirrer. Sodium hydroxide solution (50\% aqueous solution of sodium hydroxide prepared on the basis of $5 \%$ relative weight of sodium hydroxide to the weight of phenol taken) was added to the reaction mixture with constant stirring and heating. Since, the reaction was exothermic, so the reaction temperature was maintained between $50-60{ }^{\circ} \mathrm{C}$ by circulating of cold water around the resin kettle initially for two hours. Thereafter, reaction temperature was raised to $80-90{ }^{\circ} \mathrm{C}$ and setting of resinification was checked on appearance of turbidity by adding a drop of condensing resin to the cold water. Condensing resin was further heated at this temperature for another two and half hours and afterwards the resin was cooled at room temperature ${ }^{12,13}$.

\section{Preparation of the composites}

Phenol-formaldehyde $(0.75: 1)$ matrix based composites were prepared by mixing Roselle fibers and PF resin (12.7: 87.3). The mixture was then placed in the mold of a particular dimension: $40-80 \mathrm{~mm}$ (length) and $5 \times 5$ $\mathrm{mm}$ (cross section). Degasification of sample was carried-out in Compression Molding Machine and the samples were kept for curing at $120{ }^{\circ} \mathrm{C}$ for 10 minutes under $400 \mathrm{~kg} / \mathrm{cm}^{2}$ pressure. Composites thus prepared by reinforcing the raw fiber and its graft copolymers were subjected for different mechanical studies. In each case, the number of specimen used for the determination of mechanical properties was three. Tests were carried out under ambient laboratory conditions ${ }^{12,13}$.

Modulus of Rupture (MOR)

MOR was determined according to ASTM D 790 standard and was calculated using the following equations ${ }^{12,13}$ :

$$
\mathrm{MOR}=3 \mathrm{PL} / 2 \mathrm{bd}^{2} \quad \mathrm{~N} / \mathrm{mm}^{2}
$$

where: $\mathrm{P}=$ peak load, $\mathrm{L}=$ length of the sample, $\mathrm{b}=$ width of the sample and 
$\mathrm{d}=$ thickness of the sample.

Modulus of Elasticity (MOE)

MOE was determined according to ASTM D 790 standard and was calculated using the following equations ${ }^{12,13}$ :

$$
\mathrm{MOE}=\mathrm{P}_{1} \mathrm{~L}^{3} / 4 \mathrm{bd}^{3} \mathrm{y} \quad \mathrm{N} / \mathrm{mm}^{2}
$$

where: $\mathrm{P}_{1}=$ load at the limit of proportionality and $\mathrm{y}=$ rate of bending.

Stress at the Limit of Proportionality (SP)

Stress at the limit of proportionality was calculated by using the following equation ${ }^{13}$ :

$$
\mathrm{SP}=3 \mathrm{P}_{1} \mathrm{~L} / 2 \mathrm{bd}^{2} \quad \mathrm{~N} / \mathrm{mm}^{2}
$$

Hardness

Hardness of the composites was tested using Rockwell Hardness tester (Balancing Instrument and Equipments Miraj Pvt. Ltd., Model-TSM) following ASTM D785 standard. For this, B-scale was used with $100 \mathrm{Kg}$ as major load and $10 \mathrm{Kg}$ as minor load with $1 / 16$ inch indenter steel ball and was measured in HRB. HRB is the Rockwell B-scale for measurement of Hardness ${ }^{13}$

\section{Acid and base resistance}

Acid and base resistance studies were carried-out as per a method earlier reported. ${ }^{1-3,12}$. A known weight (Wi) of dry grafted sample was placed in a fixed volume $(50 \mathrm{~mL})$ of: a) $1 \mathrm{~N} \mathrm{HCl}$ and b) $1 \mathrm{~N} \mathrm{NaOH}$. The same procedure was followed by using dry ungrafted sample. In both cases, the final weight $\left(\mathrm{W}_{\mathrm{f}}\right)$ of the samples was noted down after 72 hours:

$$
\text { Weight loss }=\left[\left(\mathrm{W}_{\mathrm{i}}-\mathrm{W}_{\mathrm{f}}\right) / \mathrm{W}_{\mathrm{i}}\right] \times 100 \quad(\%)
$$

\section{RESULTS AND DISCUSSION}

Ceric ion forms complex with the cellulose through C-2 and C-3 hydroxyl groups of the anhydro glucose unit. Transfer of the electron from the cellulose molecule to Ce (IV) would leading to its reduction (Ce (III)), breakage of the $-\mathrm{OH}$ bonds at

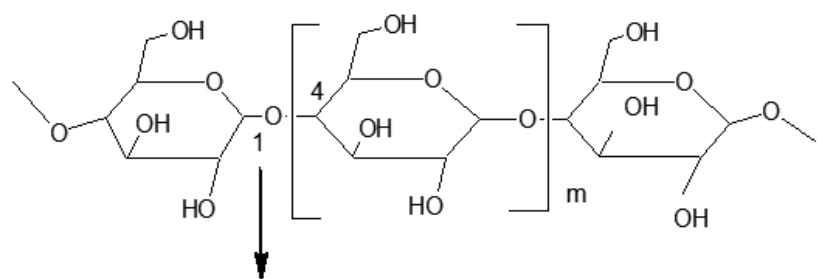

1,4 beta acetal

where, $m=2,000-26,000$

\section{Cellulose}

C-2 and C-3 and the formation of free radical sites where the monomeric chains get grafted. It has been reported that graft yield and homopolymer formation are function of both the monomer and initiator concentration ${ }^{13,17}$.

\section{Optimization of the reaction parameters}

During the graft copolymerization of BA (as a principal monomer) onto Roselle fibers, the different optimized reaction parameters to obtain the maximum graft yield $(66.80 \% ; \pm$ SD : $6.10 ; \pm$ SE: 3.52$)$ were: temperature ( $\left.{ }^{\circ} \mathrm{C}\right), 35$; time (minute), 120; CAN (mol L-1), $2.27 \times 10^{-4} ; \mathrm{HNO}_{3}\left(\mathrm{~mol} \mathrm{~L}^{-1}\right), 1.46$ $\mathrm{x} 10^{-3} ; \mathrm{BA}\left(\mathrm{mol} \mathrm{L}^{-1}\right), 1.40 \times 10^{-3}$ and $\mathrm{pH}, 7.0$.

\section{Effect of the binary monomer mixtures on percentage of grafting}

Butyl acrylate is a suitable monomer for graft copolymerization due to high reactivity, high rate of propagation $\left(\mathrm{K}_{\mathrm{p}}\right)$, low rate of termination $\left(\mathrm{K}_{\mathrm{t}}\right)$ and moderate transfer rate constant $\left(\mathrm{C}_{\mathrm{m}}\right)$. On interaction with acrylonitrile as comonomer the monomeric complex attains the much needed hydrophobichydrophilic balance to overcome the low $\mathrm{C}_{\mathrm{m}}$ of $\mathrm{AN}\left(0.10 \times 10^{4}\right)$, optimum reactivity ratios $\left[0.75 \pm 0.18: 1.52 \pm 0.03\left(60{ }^{\circ} \mathrm{C}\right)\right.$ as $\left.\mathrm{r}_{1}: \mathrm{r}_{2}\right]$ results in high $\mathrm{Pg}(100 \%)$. Since, acrylonitrile has high polarity and high $\mathrm{K}_{\mathrm{t}}$, so a higher concentration is needed in the medium. Methyl acrylate is less efficient as comonomer of butyl acrylate. Due to relatively similar nature and properties has low diffusability into fiber which decreases its Pg (44.95\%). 4-VP is ineffective due to its chemical nature, properties and the unfavorable reactivity ratio that further deteriorated its $\operatorname{Pg}(25.00 \%)$ even at high concentrations. AA as comonomer has high solubility in the reaction medium that decreases the Pg $(24.05 \%)$. Aam has higher polarity and its association with the aqueous medium further effected the grafting (Pg: $12.80 \%$ ). Vinyl acetate sterically hinders the interaction with butyl acrylate that further deteriorated the $\operatorname{Pg}(10.30$ $\%$ ) (Table 1). However, many other factors also determine the graft yield like the type of fiber, swelling, number of active sites, the nature and amount of the solvent and temperature of polymerization which strongly influence the reactivity ratios. In absence of monomer rich phase, the diluents will compete with the monomers for adsorption sites. The amount of adsorption will depend upon the total amount of surface area present and this in turn, is dependent upon the rate of stirring. Physical factors like mixing efficiency is determined by the melting temperature, the pressure, the rheological properties, solubility of the initiator and the monomer. Elevated temperature favors the degradation, reduces the initiator half life, modifies the rate or specificity of the reaction, influences the solubility and rheological parameters ${ }^{13,18-20}$.

\begin{tabular}{|c|c|c|c|c|}
\hline Sample & $\begin{array}{c}\text { Comonomer } \\
\text { x } 10^{-3} \\
\left(\mathrm{~mole} \mathrm{~L}^{-1}\right)\end{array}$ & $\begin{array}{c}\text { Mean Pg } \\
(\%)\end{array}$ & $\pm \mathrm{SD}$ & $\pm \mathrm{SE}$ \\
\hline \multirow{5}{*}{$\begin{array}{l}\text { Roselle-g-poly } \\
\text { (BA+MA) }\end{array}$} & 0.55 & 35.00 & \pm 3.57 & \pm 2.06 \\
\hline & 1.10 & $44.95^{*}$ & \pm 1.78 & \pm 1.02 \\
\hline & 1.65 & 34.00 & \pm 3.56 & \pm 2.06 \\
\hline & 2.20 & 27.90 & \pm 3.59 & \pm 2.07 \\
\hline & 2.75 & 23.15 & \pm 4.40 & \pm 2.58 \\
\hline \multirow{5}{*}{$\begin{array}{l}\text { Roselle-g-poly } \\
\text { (BA+AA) }\end{array}$} & 0.72 & 24.05 & +1.76 & +1.02 \\
\hline & 1.45 & 22.65 & \pm 3.54 & \pm 2.05 \\
\hline & 2.17 & 19.25 & \pm 6.07 & \pm 3.51 \\
\hline & 2.91 & 18.00 & \pm 6.26 & \pm 3.61 \\
\hline & 3.62 & 15.00 & \pm 4.38 & \pm 2.53 \\
\hline \multirow{5}{*}{$\begin{array}{l}\text { Roselle-g-poly } \\
\text { (BA+AN) }\end{array}$} & 1.50 & 24.50 & +1.74 & +1.01 \\
\hline & 2.25 & 58.50 & +3.57 & \pm 2.06 \\
\hline & 3.00 & $100.0^{*}$ & \pm 6.07 & \pm 3.50 \\
\hline & 3.75 & 92.00 & \pm 1.78 & \pm 1.02 \\
\hline & 4.50 & 32.50 & \pm 1.76 & \pm 1.01 \\
\hline \multirow{5}{*}{$\begin{array}{l}\text { Roselle-g-poly } \\
\text { (BA+Aam) }\end{array}$} & 1.76 & 12.80 & \pm 1.74 & \pm 1.00 \\
\hline & 3.50 & 10.81 & \pm 3.58 & \pm 2.06 \\
\hline & 5.25 & 9.62 & \pm 0.48 & \pm 0.27 \\
\hline & 7.00 & 9.00 & \pm 0.86 & \pm 0.49 \\
\hline & 8.75 & 6.00 & \pm 0.50 & \pm 0.28 \\
\hline \multirow{5}{*}{$\begin{array}{l}\text { Roselle-g-poly } \\
\text { (BA+VA) }\end{array}$} & 0.52 & 05.50 & \pm 0.89 & \pm 0.51 \\
\hline & 1.07 & 07.85 & \pm 0.86 & \pm 0.49 \\
\hline & 1.60 & 10.30 & \pm 0.47 & \pm 0.27 \\
\hline & 2.15 & 02.00 & \pm 0.87 & \pm 0.50 \\
\hline & 2.70 & - & \pm 0.47 & \pm 0.27 \\
\hline \multirow{5}{*}{$\begin{array}{l}\text { Roselle-g-poly } \\
\text { (BA+4-VP) }\end{array}$} & 0.45 & 05.80 & \pm 0.48 & \pm 0.27 \\
\hline & 0.91 & 15.85 & \pm 1.74 & \pm 1.00 \\
\hline & 1.37 & $25.00 *$ & \pm 3.57 & \pm 2.06 \\
\hline & 1.83 & 21.20 & \pm 1.78 & \pm 1.02 \\
\hline & 2.29 & 16.40 & \pm 1.79 & \pm 1.03 \\
\hline
\end{tabular}

Table 1. Effect of the binary mixture composition on Pg using BA (1.40 $\times 10^{-3}$ mole $^{-1}$ ) as principal monomer.

where, ${ }^{*}$ refers to the effective $\mathrm{Pg}, \mathrm{SD}$ and SE refer to standard deviation and standard error. 


\section{$X$-Ray diffraction studies of graft copolymers}

$X$-ray diffraction studies were performed under ambient conditions, using $\mathrm{Cu} \mathrm{K \alpha}(1.5418 \AA)$ radiation, Ni-filter and scintillation counter at $40 \mathrm{KV}$ and $40 \mathrm{~mA}$ on rotation between $13{ }^{\circ}$ to $25^{\circ}$ at $2 \theta$-scale and 1 sec. step size. Increment of 0.01 degree with $0.5^{\circ}$ or $1.0 \mathrm{~mm}$ of divergent and anti-scattering slit and calibrated by corundum. The continuous scans were taken and different d-spacing $(\AA)$ and relative intensities (I) were obtained (Fig.1). The counter reading of highest peak intensity near $22.68^{\circ}$ represents crystalline material and the peak near $15.0^{\circ}$ in the halo-pattern corresponds to the amorphous material in the cellulose. Degree or percentage of crystallinity $(\% \mathrm{Cr})$ and crystallinity index (C.I.) were calculated as per the following methods. ${ }^{12,13}$

$$
\begin{aligned}
& \% \mathrm{Cr}=\left[\mathrm{I}_{22.68} /\left(\mathrm{I}_{22.68}+\mathrm{I}_{15.00}\right)\right] \times 100 \\
& \text { C.I. }=\left[\left(\mathrm{I}_{22.68}-\mathrm{I}_{15.00}\right) / \mathrm{I}_{22.68}\right] \times 100
\end{aligned}
$$

where: $I_{2268} I_{1500}$ peak intensities of crystalline and amorphous content at $2 \theta$-scale close to $22.68^{\circ}$ and $15.00^{\circ}$, respectively.

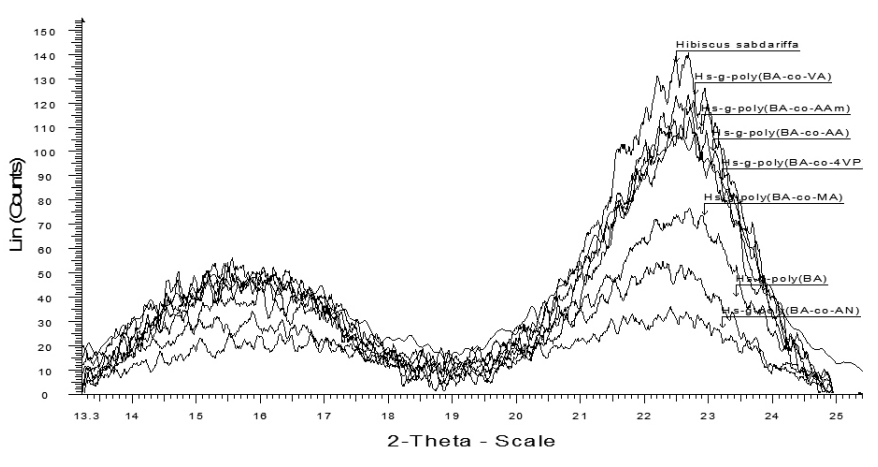

Fig. 1 The X-ray powder overlay of Roselle-g-poly(BA + vinyl monomer) vis-à-vis H. sabdariffa.

\begin{tabular}{|c|c|c|c|c|c|}
\hline \multirow[t]{2}{*}{ Sample } & \multirow{2}{*}{$\begin{array}{c}\mathrm{Pg} \\
(\%)\end{array}$} & \multicolumn{2}{|c|}{$\underline{2 \theta \text { Scale }}$} & \multirow[t]{2}{*}{$\% \mathrm{Cr}$} & \multirow[t]{2}{*}{ C.I. } \\
\hline & & $I_{15}$ & $\mathrm{I}_{22.68}$ & & \\
\hline Roselle & - & 40 & 136 & 77.20 & 0.70 \\
\hline Roselle-poly(BA-co-VA) & 10.30 & 42 & 126 & 75.00 & 0.66 \\
\hline Roselle-poly(BA-co-Aam) & 12.80 & 40 & 119 & 74.84 & 0.66 \\
\hline Roselle-g-poly(BA-co-AA) & 24.05 & 38 & 111 & 75.00 & 0.65 \\
\hline Roselle-g-poly(BA-co-4-VP) & 25.00 & 35 & 104 & 74.82 & 0.66 \\
\hline Roselle-g-poly(BA-co-MA) & 44.95 & 28 & 75 & 72.81 & 0.62 \\
\hline
\end{tabular}

Table 2. \%Cr and C.I. of the Roselle fiber and its graft copolymers.

where: $\% \mathrm{Cr}=$ percentage of crystallinity, C.I. $=$ crystallinity index.

\section{FTIR and SEM studies}

Using butyl acrylate as the principal monomer, a peak associated to the $\mathrm{C}=\mathrm{O}$ stretching in all cases was observed. Other bands from the secondary monomers were observed at $2246 \mathrm{~cm}^{-1}$ (-CN group) in Roselle-g-poly(BA-coAN); $1638 \mathrm{~cm}^{-1}$ (vinyl group) in Roselle-g-poly(BA-co-4-VP); $2929 \mathrm{~cm}^{-1}(-\mathrm{OH}$ group) in Roselle-g-poly(BA-co-AA); $1648 \mathrm{~cm}^{-1}$ (vinyl group) in Roselle-gpoly(BA-co-VA); $1738 \mathrm{~cm}^{-1}$ ( $\mathrm{C}=\mathrm{O}$ group) in Roselle-g-poly(BA-co-MA); at $3442 \mathrm{~cm}^{-1}(\mathrm{~N}-\mathrm{H})$ in Roselle-g-poly(BA-co-Aam). FTIR spectrum of the P-F resin showed peaks at $3422 \mathrm{~cm}^{-1}$ (-OH stretch), $2920 \mathrm{~cm}^{-1}$ (C-H aromatic stretch), $1610 \mathrm{~cm}^{-1}$ and $1509 \mathrm{~cm}^{-1}(\mathrm{C}=\mathrm{C}$ stretch). Other peaks were found at $1465 \mathrm{~cm}^{-1}\left(\mathrm{CH}_{2}\right.$ bend $)$ and $1235 \mathrm{~cm}^{-1}$ (C-O stretch of the phenol unit).

SEM of the raw and the highest grafted graft copolymer clearly distinguish the change in morphology brought about by grafting, depending on the Pg (Fig. $2 \mathrm{a}$ and $2 \mathrm{~b}$, respectively). Since the bio-composites did not evidence conducting behavior, they were gold plated to have an impact. The SEM results help to distinguish between the phenoplast and the fiber reinforced composite (Fig. 3a and $3 \mathrm{~b}$, respectively).
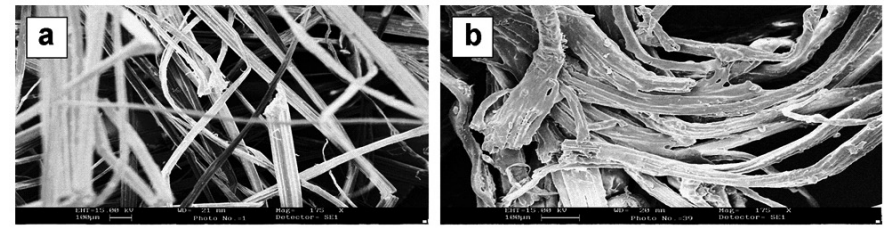

Fig. 2. SEM $(175 \mathrm{x})$ of a) Roselle raw and b) highest grafted Roselle-gpoly(BA-co-AN).
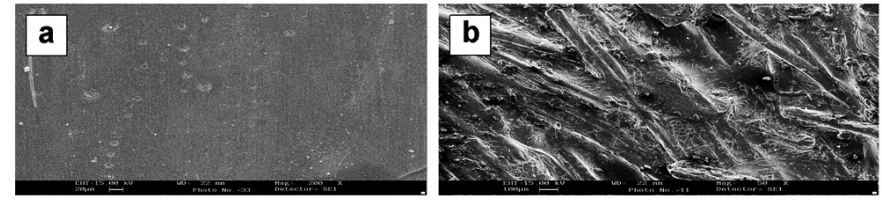

Fig. 3. SEM of a) P-F resin raw (200 x) and b) reinforced Roselle-P-F composite $(50 \mathrm{x})$.

Percentage of crystallinity and crystallinity index of graft copolymers

It is evident from Fig. 1 and Table 2 that the grafting process for all the Roselle-g-copolymer systems diminishes the $\% \mathrm{Cr}$ and C.I. parameters of a pure Roselle fiber sample. In case of raw Roselle fiber the \% $\mathrm{Cr}$ and C.I. are higher and the incorporation of the monomer chains to the back-bone has impaired the crystallinity. Crystallinity index gives a quantitative measure of the orientation of the cellulose crystals in the fibers. A lower crystalline index in case of graft co-polymers means poor order of arrangement of cellulose crystals in the fiber, that is due to dis-orientation of the cellulose crystalline lattice to the fiber axis during grafting. The individual diffraction pattern of the raw Roselle fiber (Fig. 4a) and highest grafted sample (Fig. 4b) depicts the d-values and further elaborates the differences between the two on the basis of the peak type and peak intensity. There was significant conversion of the sharp peaks in crystalline raw form to the hallo pattern in the highest grafted Roselle-g-poly(BA-co-AN) due to the accumulation of the amorphous content. However, the diffractogram of the unmodified Roselle fiber and the treated samples confirmed that cellulose I form remained unchanged after graft copolymerization under the optimized reaction conditions. ${ }^{13,18-20}$

\section{Acid and base resistance}

It was observed that acid-base resistance of the Roselle fiber increased with the grafting process This is due to the fact that poly(vinyl) chains grafted onto Roselle fiber have less affinity for the $1 \mathrm{~N} \mathrm{HCl}$ and $1 \mathrm{~N} \mathrm{NaOH}$ solutions as compared to free hydroxyl groups present in ungrafted fiber. Therefore, the resistance of fiber towards acid-base was found to increase with the incorporation of poly(vinyl) chains on the active sites of the backbone (Table 3). ${ }^{1-3,12,13}$

Table 3. Chemical resistance studies of composite, graft copolymers visà-vis back bone.

\begin{tabular}{|l|c|c|c|}
\hline Sample & Pg & $\begin{array}{c}\text { \% Wt. loss } \\
\text { in 1N HCl }\end{array}$ & $\begin{array}{c}\text { \% Wt. loss } \\
\text { in 1N NaOH }\end{array}$ \\
\hline Roselle & - & 55.0 & 43.0 \\
\hline Roselle-g-poly(BA) & 66.80 & 37.0 & 26.0 \\
Roselle-g-poly(BA-co-4VP) & 10.30 & 12.0 & 08.0 \\
Roselle-g-poly(BA-co-Aam) & 12.80 & 50.0 & 38.0 \\
Roselle-g-poly(BA-co-AA) & 24.05 & 38.0 & 30.0 \\
\hline Roselle-g-poly(BA-co-4VP) & 25.00 & 38.0 & 28.0 \\
\hline Roselle-g-poly(BA-co-MA) & 44.75 & 29.0 & 25.0 \\
\hline Roselle-g-poly(BA-co-AN) & 100.0 & 5.0 & 2.0 \\
Phenoplast & - & 4.0 & 2.0 \\
Roselle-r-PF-composite & - & 1.0 & - \\
\hline
\end{tabular}

where: -r-PF refers to reinforced phenol-formaldehyde resin. 

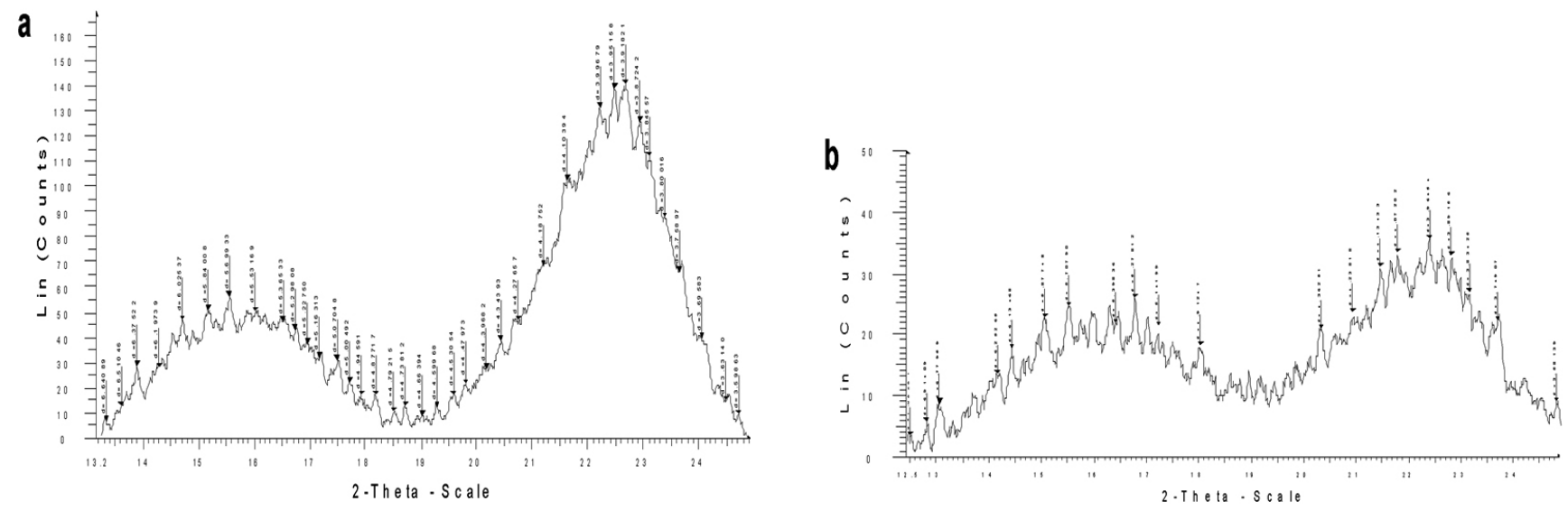

Fig. 4. The XRD pattern of a) raw Roselle fiber and b) highest grafted Roselle-g-poly(BA-co-AN).

Table 4. MOR, MOE, SP and hardness studies of graft copolymers reinforced PF composite vis-à-vis PF resin.

\begin{tabular}{|c|c|c|c|c|}
\hline \multirow[b]{2}{*}{ Composite } & \multicolumn{4}{|c|}{ Strength Test $( \pm$ SD $)$} \\
\hline & $\operatorname{MOR}\left(\mathbf{N} / \mathbf{m m}^{2}\right)$ & $\operatorname{MOE}\left(\mathbf{N} / \mathbf{m m}^{2}\right)$ & $\begin{array}{c}\text { SP } \\
\left(\mathbf{N} / \mathbf{m m}^{2}\right)\end{array}$ & $\begin{array}{c}\text { Hardness } \\
\text { (HRB) }\end{array}$ \\
\hline Phenol-formaldehyde resin & 43.20 & 496.12 & 38.40 & Brittle \\
\hline Roselle-r-PF & 69.99 & 614.40 & 57.60 & 67.00 \\
\hline Roselle-g-poly(BA)-r-PF & 75.16 & 720.60 & 66.00 & 70.00 \\
\hline Roselle-g-poly(BA-co-MA)-r-PF & 83.62 & 780.00 & 77.00 & 65.00 \\
\hline Roselle-g-poly(BA-co-AN)-r-PF & 73.20 & 692.92 & 68.00 & 70.00 \\
\hline Roselle-g-poly(BA-co-4VP)-r-PF & 74.40 & 700.80 & 69.56 & 75.00 \\
\hline
\end{tabular}

where: -r-PF refers to reinforced phenol-formaldehyde resin.

\section{Mechanical evaluation of the bio-composites}

Amongst all the graft copolymers synthesized, only the three highest grafted copolymers obtained in binary mixtures and the raw fiber were used as reinforcement in the polymer matrix based composites for the mechanical evaluation, in reference to the phenoplast and Roselle-reinforced PF composite (Table 4).

The better mechanical strength in composites reinforced with graft copolymers in comparison to the raw fiber could be due to the reinforced strength provided by the monomer incorporated during graft copolymerization. However, some deviations in the results could be justified by the factors like nature, amount of matrix and fiber, orientation, distribution of the fiber with respect to the matrix axis, form of reinforcement used (woven or non-woven, grafted or ungrafted), strength of the interfacial bond between the fiber and matrix, length of the fiber (continuous or discontinuous), aspect ratio that on mere imbalance may lead to debonding and cracking. ${ }^{12,13,14,20}$

\section{CONCLUSIONS}

Graft copolymerization of butyl acrylate and its binary vinyl monomeric mixtures onto Roselle fiber increased the chemical resistance and decreased the $\% \mathrm{Cr}$ and C.I. of the fiber. However, the cellulose form I remained unchanged after graft copolymerization, under the optimized reaction conditions. The use of these graft copolymers in phenoplast as reinforcement increased the chemical resistance and mechanical strength. These noble materials procured from renewable waste bio-mass could be used in insulator, transportation, packaging and aerospace for better scientific application and advancement of technology.

\section{REFERENCES}

[1] B. S. Kaith, A. S. Singha, K.S. Sharma, International Journal of Chemical Science, 2, 37 (2004)

[2] B.S. Kaith, A. S., Singha, K.S. Sharma, Journal of Polymeric Materials,
20, $195(2003)$

[3] A.S. Singha, B. S., Kaith, S. Kumar, International Journal of Chemical Science 2(3), 472 (2004).

[4] B. S. Kaith, A.S. Singha, D. K. Dwivedi, S. Kumar, D. Kumar, D. Dhemeniya, International Journal of Plastic Technology, 7, 119 (2003).

[5] V. Kumar, Y. K. Bhardwaj, K.P. Rawat, S. Sabharwal, Radiation Physics Chemistry, 73, 175 (2005).

[6] J. S. Lee, N. R. Kumar, H. D. Rozman, B. M. N. Azemi, Food Chemistry, 91, 203 (2005).

[7] V. Singh, D. N. Tripathi, A. Tiwari, R. Sanghi, Carbohydrate Polymer, 65, 41 (2006)

[8] A. Mishra, M. Bajpai, Journal of Hazardous Material, 118, 213 (2005)

[9] W. E. Rudzinski, A. M. Dave, U. H. Vaishnav, S. G. Kumbar, A. R. Kulkarni, T. M. Aminabhavi, Designing Monomers and Polymer, 5, 39 (2002).

[10] M. El-Sherbiny, E. M. D. Abdel-Bary, R. K. Harding, Journal of Applied Polymer Science, 102, 977 (2006).

[11] L. Y. Mwaikambo, M. P. Ansell, Journal of Applied Polymer Science, 84, 2222 (2002).

[12] Susheel, Kalia, Development of Polymer Matrix based Composites using Grafted Flax Cellulose as Reinforcing Agent and Evaluation of some of the Mechanical and Chemical Properties, Thesis, Chapter $4^{\text {th }}(2007)$.

[13] Ashish Chauhan Synthesis and Evaluation of Physico-ChemicoMechanical Properties of Polymer Matrix based Composites using Graft Copolymers of Hibiscus sabdariffa as Reinforcing Agents, Ph. D. Thesis, Punjab Technical University, Chapter 5 (2009).

[14] S. A. Chawala, Text Book of Engineering Chemistry, Polymers, Dhanpat Rai \& Co., 22.32 (2002).

[15] M. S.Thacker, Raw Materials, Malvaceae, The Wealth of India, A Dictionary of Indian Raw Materials \& Industrial products, CSIR Publisher, New Delhi, Vol. V, H-K: 80 (2002).

[16] J. Junkasem, J. Menges, P. Supaphol,. Journal of Applied Polymer Science, 101, 3291(2006) 
[17] G. Mino, S. Kaizerman, Journal of Applied Polymer Science, 31, 242 (1958).

[18] J. Brandrup, E. H. Immergut, Polymer Handbook, Wiley Interscience, John Wiley and Sons, New York, 2,:II-105 (1975).

[19] G. Ham, High Polymer, Copolymerization, Interscience Publishers, 18,
698 (1964)

[20] J. R. Fried, Conformation, solution, and molecular weight In Polymer Science and Technology, $2^{\text {nd }}$ Edition, 43, Upper saddle river, NJ: Prentice Hall Professional Technical Reference (2004). 